\title{
A PERSPECTIVA DECOLONIAL NOS CURSOS DE FORMAÇÃO DE PROFESSORES: uma revisão de literatura
}

\author{
LA PERSPECTIVA DECOLONIAL EN LOS CURSOS DE FORMACIÓN DE \\ PROFESORES: una revisión de la literatura
}

\section{THE DECOLONIAL PERSPECTIVE IN TEACHER TRAINING COURSES: a literature review}

\section{Fabiana de Freitas Poso ${ }^{1}$}

ORCID: https://orcid.org/0000-0003-0589-3031

Bruno Andrade Pinto Monteiro 2

ORCID: https://orcid.org/0000-0001-8933-5816

\begin{abstract}
Resumo
Este texto traz reflexões sobre o processo de decolonialidade, o qual questiona a lógica hegemônica de uma cultura comum, de base ocidental e eurocêntrica e que ainda é dominante nas instituições educativas. Ele apresenta um panorama descritivo a partir do estado da arte de vinte e seis artigos selecionados do Google Acadêmico, que fizeram ponderações acerca da perspectiva decolonial nos cursos de formação de professores, demonstrando a necessidade dos mesmos superarem a racionalidade técnica e de estarem comprometidos com a construção identitária deste futuro docente. Criando, desta forma, situações de interlocução para o aparecimento das insurgências contrárias a estes modelos hegemônicos.
\end{abstract}

Palavras-chave: Modernidade/Colonialidade. Pedagogia decolonial. Formação de professores.

\section{Resumen}

Este texto trae reflexiones sobre el proceso de decolonialidad, que cuestiona la lógica hegemónica de una cultura común, de base occidental y eurocéntrica y que sigue siendo dominante en las instituciones educativas. Presenta un panorama descriptivo basado en el estado del arte de veintiséis artículos académicos seleccionados de Google Académico, que hizo consideraciones sobre la perspectiva decolonial en los cursos de formación de profesores, demostrando la

\footnotetext{
${ }^{1}$ Doutoranda em Educação em Ciências e Saúde (UFRJ). Colaboradora do Laboratório de Linguagens e Mediações da UFRJ.Professora da SEEDUC e SME. E-mail: bianabia@bol.com.br

${ }^{2}$ Doutor em Educação em Ciências e Saúde (UFRJ). Professor do Programa de Pós-Graduação em Educação em Ciências e Saúde da UFRJ. Professor do Mestrado Profissional em Ensino de Química da UFRJ. Professor Adjunto da UFRJ - Campus Macaé. E-mail: bpmonteiro@gmail.com
}

\section{Como referenciar este artigo:}

POSO, F.F.; MONTEIRO, B.A.P. A perspectiva decolonial nos cursos de formação de professores: uma revisão de literatura. Revista Pedagógica, v. 23, p. 1-18, 2021. 
necesidad de que superen la racionalidad técnica y se comprometan con la construcción de identidad de este futuro docente. De esta manera, son creadas situaciones de interlocución para la aparición de insurgencias contrarias a estos modelos hegemónicos.

Palabras clave: Modernidad/Colonialidad. Pedagogía decolonial. Formación de profesores.

\begin{abstract}
This text brings reflections on the process of decoloniality, which questions the hegemonic logic of a common culture, of western and Eurocentric base and which is still dominant in educational institutions. It presents a descriptive overview from the state of the art of twenty-six selected Google Scholar articles, which made considerations about the decolonial perspective in teacher training courses, demonstrating the need for them to overcome technical rationality and to be committed to the identity construction of this future teacher. In this way, creating situations of dialogue for the appearance of insurgencies contrary to these hegemonic models.
\end{abstract}

Keywords: Modernity/Coloniality. Decolonial pedagogy. Teacher training.

\title{
INTRODUÇÃO
}

Os muros das unidades escolares, segundo Miranda (2013), são interpretados como um dos processos de colonização do conhecimento, pois se sustentam ainda em orientações eurocêntricas. Esta observação apresenta-se como subproduto do sistema capitalista em que vivemos, altamente dependente e hierarquizado. Dessa forma, as políticas curriculares do que ensinar, do que avaliar e do que adotar como prática pedagógica têm se comportado como um marco conformador e controlador do trabalho e das identidades profissionais. Em vista disso, nota-se uma marginalização cultural, com a seleção e supremacia de um único tipo de cultura, induzindo os privilegiados que se ligam à cultura dominante, a adquirirem cada vez mais educação especializada e, os menos favorecidos, o fracasso escolar e o consequente distanciamento do mundo cultural (SACRISTÁN, 2000).

Diante deste cenário supracitado, Arroyo (2006 apud FERREIRA, 2011) argumenta se mesmo após termos discursado na contemporaneidade sobre a diversidade, se ainda estamos agindo, planejando e organizando o currículo como se os alunos fossem um bloco homogêneo e ainda como se convivêssemos com um protótipo único de aluno. Metaforicamente, é como se tivéssemos experienciando o mesmo tipo de educação constatada no Brasil colônia com desaculturação das identidades indígenas e negras e aculturação, de modo subalterno, à cultura branca. 
É nesse contexto que surge o termo decolonialidade, num processo dinâmico, de movimento, de conectividade, articulação, inter-relação, de visibilidade das lutas contra a colonialidade, de pensar na estruturação de outros modos de viver, de possibilitar críticas ao eurocentrismo por parte dos saberes silenciados, de permitir uma forma de se autocompreender, de respeitar a alteridade de outras culturas presentes ao redor, etc. Sua meta é a reconstrução do ser, do poder e do saber. Para Mignolo (2014) não é um método a aplicar, mas uma forma de estar no mundo, agindo e pensando sobre esse mundo.

O pensar decolonial trata de romper com os universalismos alienantes e coloca em pauta os binarismos modernos: norte/sul, ocidente/oriente, colonizador/colonizado, rico/pobre, cultura/natureza, branco/negro, homem/mulher, ciência/arte, etc. Ele problematiza as hierarquias e legitima processos anti-hegemônicos (MOURA, 2017).

Podemos também discorrer sobre o termo pedagogia decolonial fomentado por Catherine Walsh, que trouxe a ideia de uma práxis baseada numa insurgência educativa propositiva com a viabilidade da criação e construção de novas condições sociais, políticas, culturais e de pensamento. Neto (2018, p. 6) afirma que "[...] ela incita possibilidades de estar, ser, sentir, existir, fazer, pensar, olhar, escutar e saber de outro modo”. Ela reverbera que educar é um ato político, numa dimensão emancipadora e transformadora; além de interpelar que a humanização pressupõe a decolonização.

Vale também destacar o termo interculturalidade levantado por Walsh (2007)como forma de resistência histórica e atual dos povos indígenas e negros às construções de um projeto social, cultural, político, ético e epistêmico; apontando processos de confronto com o neocapitalismo, numa ruptura epistêmica baseada na dominação, exploração e marginalização.

Diante das questões alavancadas, é preciso pensar a sala de aula como lugar de resistência aos modelos de políticas públicas de educação que converge com os ideais neoliberais, visando a padronização bancária das práticas de ensino-aprendizagem, pautadas na concepção de um saber entendido como acabado, completo e que, portanto, não precisa ser questionado nem tampouco reformulado (BRUNO, 2018). Neste sentido, é inexorável que essas discussões, referentes às desigualdades étnico-raciais sejam abordadas, refletidas e problematizadas para a formação de jovens críticos, que se 
sensibilizem e consigam problematizar a presença de marcas históricas de séculos de colonização.

Destarte, uma formação de professores que possa pleitear a valorização das multiculturas, problematizando axiomas, sacudindo as certezas, respeitando as diferenças, superando a racionalidade técnica e que esteja engajada com a construção identitária deste futuro docente, almejando uma educação democrática, inclusiva e comprometida com a emancipação social é um caminho frutífero para alcançar as apetecidas transformações.

Desta forma, este trabalho teve por objetivos apresentar um panorama descritivo dos artigos que tratam da pedagogia decolonial nos cursos de formação inicial e continuada de professores, investigar quais são as principais abordagens destes trabalhos frente a esta temática e se há sugestões decoloniais em seus corpos textuais para os cursos de formação docente.

\section{FORMAÇÃO DE PROFESSORES E DECOLONIALIDADE}

A identidade docente não é um dado imutável, mas é um processo de construção do sujeito historicamente situado. Em consonância com Pimenta (1997), uma identidade profissional se constrói a partir da revisão das tradições, da análise sistemática das práticas à luz das teorias existentes, da construção de novas teorias, do significado que cada professor confere à atividade docente no seu cotidiano, de seu modo de situar-se no mundo, de sua história de vida, bem como de seus saberes, etc.

É importante ressaltar a necessidade de a licenciatura ser encarada como um momento de socialização agregando os licenciandos ao dia-a-dia da escola, pois como afirma Lopes (2009, p. 87) "a prática é situada como a base para a construção do conhecimento do professor, pois nessas formulações só a realidade pode informar o conhecimento que importa, que é reconhecido como o verdadeiro para as questões que atingem a educação".

No entanto, conforme observado por Gatti (2010), Veiga (2012) e Poso e Monteiro (2017), muitos cursos apresentam um caráter descontextualizado, um perfil descritivo que não atende a demanda da escola. Brasil (2001) afirma, que salvo raríssimas exceções, a 


\section{REVISTA}

ênfase ou é dada à transposição didática sem muitas discussões e reflexões ou com atenção acentuada a um conteudismo que este profissional deverá aprender.

Ressaltamos que o abismo entre teoria e prática reflete na insegurança por parte destes principiantes ao se defrontarem com situações imprevisíveis. Assim, o que se observa é que quando não há embasamentos consistentes na formação docente, a tendência do professor é reativar sua memória de aluno, pois como afirma Dias (2012), esta é a única profissão em que o estudante possui 15 e/ou 16 anos de estágio, pois desde muito pequenos estamos mergulhados neste lugar.

Desse modo, nossa propensão é a de naturalizar as coisas e os modos de fazer e aplicá-los sem pensar. Uma formação inventiva, ao contrário, tenciona estes territórios existenciais para derivar e constituir outros modos de pensar e fazer a formação e a escola. Ela não tem a finalidade de dizer o que devem fazer ou ainda de transmitir competências. O intuito é polemizar as naturalizações acolhidas e os postulados, estremecendo as certezas, os modos de fazer e de pensar.

Vários autores discorrem sobre a colonialidade reproduzida nos cursos de formação de professores; dentre eles, podemos citar Silvestre (2016), ao elucidar que sua marca colonial é constituída pela relação assimétrica entre aquele que ensina e aquele que aprende a ser professor. Já Rozo (2004, p. 156-157 apud ROCHA, 2017) diz que "[...] a universidade segue pensando um mundo complexo de forma simples; continua formando profissionais arborescentes, cartesianos, disciplinários, incapazes de intervir em um mundo que funciona com uma lógica complexa”. Bruno (2018) também corrobora enunciando sobre a ausência de debates críticos a respeito das continuidades do processo colonizatório na esfera epistemológica, além da reprodução de práticas formativas colonizadoras. E para finalizar, Rocha (2017) reflete sobre a compartimentalização tanto acerca dos conhecimentos, assim como na própria divisão dos departamentos separando os professores de acordo com seus saberes. Salientamos, também embasados em Dias e Lopes (2003), a influência do mundo globalizado moldando os conceitos em eficiência, produtividade, avaliação do desempenho, promoção por mérito dos professores, etc.

Como alternativa a esse cenário, Mignolo (2014) discute o conceito de desobediência epistêmica com desprendimento do eurocentrismo. Ou seja, segundo o autor seria “[...] pensar o nosso, qualquer que seja a história local em que 'o nosso' tenha 
sentido" (p. 67). Acrescentamos que este olhar decolonial sobre os cursos de formação de professores permite repensar os binarismos (teoria e prática, professor e aluno, transmissor de conhecimento e receptor desse conhecimento, pesquisa e sala de aula, entre outros) e reconhecer que este é um espaço de entrecruzamento de diversos saberes e que devem ser estabelecidas relações mais simétricas entre seus agentes.

Há necessidade de amplas discussões com problematização das injustiças sociais e abordagens de diversidade cultural, objetivando a democratização e o respeito entre todos. Há também a premência de andar na contramão da mecanização do processo ensino-aprendizagem, desassociando-se do modelo bancário e levando os licenciandos a refletirem sobre a profissão docente e a importância da atuação no magistério com práticas que sirvam para combater padrões educacionais que valorizem determinada cultura em detrimento de outra; que postulem uma única verdade; que façam da escola uma via de mão única, onde o professor é tido como o detentor do saber (ROCHA, 2017).

Mateus (2013) devaneia a favor da parceria entre professores da universidade, professores licenciandos e professores da escola, dando novos contornos à relação escolauniversidade e desestruturando as relações hegemônicas de poder e saber. É neste contexto também que Zanlorenzi e Oliveira (2017) consideram significativos processos de formação continuada não mais para os professores, mas com os professores, construção coletiva a favor das demandas locais, sem perder de vista o global.

\section{CAMINHOS PERCORRIDOS}

Em busca de alcançar os objetivos do trabalho foi feito um levantamento dos artigos que discorriam sobre a pedagogia decolonial nos cursos de formação de professores, utilizando as seguintes bases: Redalyc, Eric, Portal de Periódicos e Google Acadêmico. O quadro 1 mostra os resultados diante dos descritores empregados:

Quadro 1 - Relação do quantitativo de trabalhos encontrados

\begin{tabular}{|c|c||c|}
\hline & $\begin{array}{c}\text { "pedagogia decolonial" and } \\
\text { "formação de professores" }\end{array}$ & $\begin{array}{c}\text { "pedagogia decolonial" and } \\
\text { "formação docente" }\end{array}$ \\
\hline Redalyc & 5426 & 1964 \\
\hline Eric & 0 & 0 \\
\hline Portal de Periódicos & 3 & 1 \\
\hline
\end{tabular}


Revista do Programa de Pós-Graduação em Educação da Unochapecó ISSN 1984-1566 (on-line) ISSN 1415-8175 (impressa)

\begin{tabular}{|l|l||r} 
Google Acadêmico & 343 & 226
\end{tabular}

Fonte: dados da pesquisa (2020).

Estes descritores foram aplicados em busca avançada e ocorrendo em qualquer parte do texto. Diante do montante detectado na base Redalyc, da pouca expressividade no Portal de Periódicos e nenhum artigo encontrado na Eric, optou-se pelo Google Acadêmico.

Teses, dissertações, livros, citações, anais de congressos e artigos repetidos foram excluídos. Subsequentemente foi feita a leitura dos títulos e resumos, pois alguns mencionavam, mas não faziam referências especificamente aos objetivos deste trabalho ou abordavam de forma perfunctória a pedagogia decolonial ou a formação de professores. Desta forma, dos 343 identificados na primeira busca no Google Acadêmico, apenas 42 continuaram. Já com relação à segunda, somente 31 (no entanto 26 já haviam aparecido na primeira busca). Posteriormente, foi utilizado novo critério de exclusão; aqueles artigos atinentes a revistas não categorizadas como $A 1, A 2, B 1$ e $B 2$ na área de Educação pelo Qualis de 2016 foram suprimidos. Destarte, remanesceram 26 artigos que seguiram para serem analisados, conforme Quadro 2:

Quadro 2 - Artigos analisados.

\begin{tabular}{|c|c|c|c|c|}
\hline CÓDIGO & ARTIGO & ANO & REVISTA & QUALIS \\
\hline T1 & $\begin{array}{c}\text { A estética negra de Zózimo Bulbul em cena: } \\
\text { novas possibilidades para pensar cinema, } \\
\text { currículo e formação de professores }\end{array}$ & 2017 & Educação Temática Digital & A1 \\
\hline T2 & $\begin{array}{c}\text { A formação de professores e o "ser mais" } \\
\text { indígena }\end{array}$ & 2017 & $\begin{array}{c}\text { Revista de } \\
\text { Educação Pública }\end{array}$ & A2 \\
\hline T3 & $\begin{array}{c}\text { A implementação da lei 10.639/2003 no } \\
\text { estado de Mato Grosso do Sul e a formação } \\
\text { continuada de professores: uma perspectiva } \\
\text { emancipatória e decolonial }\end{array}$ & 2017 & $\begin{array}{c}\text { Revista Contemporânea de } \\
\text { Educação }\end{array}$ & B2 \\
\hline T4 & $\begin{array}{c}\text { Desafios curriculares no ensino superior: } \\
\text { contribuições do Programa Abdias } \\
\text { Nascimento }\end{array}$ & 2019 & Revista Eletrônica de \\
Educação & B1 \\
\hline T5 & $\begin{array}{c}\text { Em buscional de Educação (PNE), Formação de } \\
\text { professores e multi/interculturalismo }\end{array}$ & 2013 & $\begin{array}{c}\text { Ensaio - Avaliação e } \\
\text { Políticas Públicas em } \\
\text { Educação }\end{array}$ & A1 \\
\hline T6 & $\begin{array}{c}\text { Escrevendo cartas: a sexualidade na vida e } \\
\text { na formação docente de Biologia }\end{array}$ & 2019 & Ensino em Revista & B2 \\
\hline T7 & $\begin{array}{c}\text { Experiências de estudantes mapuches em } \\
\text { formação inicial docente no contexto de } \\
\text { diversidade }\end{array}$ & 2017 & Psicologia Escolar e \\
Educacional & A2
\end{tabular}


REVISTA

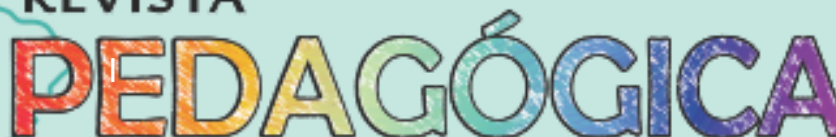

\section{Revista do Programa de Pós-Graduação em Educação da Unochapecó ISSN 1984-1566 (on-line) ISSN 1415-8175 (impressa)}

\begin{tabular}{|c|c|c|c|c|}
\hline T8 & $\begin{array}{c}\text { Extensão universitária: contribuições de } \\
\text { professores Guarani para a formação inicial } \\
\text { de professores de matemática }\end{array}$ & 2018 & Espaço Pedagógico & B1 \\
\hline T9 & $\begin{array}{c}\text { Formação continuada de professores } \\
\text { Guarani: um estudo de conceito sobre } \\
\text { números naturais }\end{array}$ & 2018 & Zetetike & B1 \\
\hline T10 & $\begin{array}{c}\text { Formação de professores e relações étnico- } \\
\text { raciais (2003-2014): produção em teses, } \\
\text { dissertações e artigos }\end{array}$ & 2018 & Educar em Revista & $\mathrm{A} 1$ \\
\hline T11 & $\begin{array}{l}\text { Formação de professores Guarani e Kaiowá: } \\
\text { relações entre territorialidade, processos } \\
\text { próprios de aprendizagem e escola }\end{array}$ & 2013 & $\begin{array}{l}\text { Teoria e Prática da } \\
\text { Educação }\end{array}$ & B1 \\
\hline T12 & $\begin{array}{c}\text { Formação dos professores para as } \\
\text { modalidades educação especial e educação } \\
\text { indígena: espaços intersticiais }\end{array}$ & 2016 & Educação & $\mathrm{A} 2$ \\
\hline T13 & $\begin{array}{c}\text { Formação dos professores para o } \\
\text { atendimento educacional especializado em } \\
\text { contexto indígena }\end{array}$ & 2016 & Linhas Críticas & B1 \\
\hline T14 & $\begin{array}{c}\text { Inter/multiculturalidade e formação } \\
\text { continuada de educadores: o protagonismo } \\
\text { do movimento social negro por uma } \\
\text { Pedagogia Decolonial }\end{array}$ & 2014 & $\begin{array}{l}\text { Série-Estudos - Periódico do } \\
\text { Programa de Pós- } \\
\text { Graduação em Educação da } \\
\text { UCDB }\end{array}$ & B1 \\
\hline T15 & $\begin{array}{l}\text { Interculturalidade na formação de } \\
\text { professores do campo: análise de uma } \\
\text { experiência }\end{array}$ & 2017 & $\begin{array}{l}\text { Revista Brasileira de } \\
\text { Educação do Campo }\end{array}$ & $\mathrm{B} 2$ \\
\hline T16 & $\begin{array}{c}\text { Interculturalidade nas escolas: um estudo } \\
\text { sobre práticas didáticas no Pibid }\end{array}$ & 2018 & Educação \& Realidade & $\mathrm{A} 1$ \\
\hline T17 & $\begin{array}{c}\text { Movimentos, organizações sociais e ações } \\
\text { coletivas na formação de professores }\end{array}$ & 2014 & Nómadas & B1 \\
\hline $\mathrm{T} 18$ & $\begin{array}{l}\text { Multiculturalismo e formação de } \\
\text { professores: dimensões, possibilidades e } \\
\text { desafios na contemporaneidade }\end{array}$ & 2018 & $\begin{array}{l}\text { Ensaio: Avaliação e Políticas } \\
\text { Públicas em Educação }\end{array}$ & $\mathrm{A} 1$ \\
\hline T19 & $\begin{array}{l}\text { O diálogo intercultural e a formação de } \\
\text { professores na ANPED (2002-2015): há a } \\
\text { inclusão ou exclusão? }\end{array}$ & 2017 & $\begin{array}{l}\text { Revista Online de Política e } \\
\text { Gestão Educacional }\end{array}$ & $\mathrm{B} 2$ \\
\hline T20 & $\begin{array}{c}\text { O ensino de português: lições de um } \\
\text { professor indígena }\end{array}$ & 2015 & Currículo sem Fronteiras & $\mathrm{A} 2$ \\
\hline T21 & $\begin{array}{l}\text { Os processos próprios de aprendizagem e a } \\
\text { formação dos professores indígenas }\end{array}$ & 2012 & Práxis Educativa & $\mathrm{A}_{2}$ \\
\hline T22 & $\begin{array}{c}\text { Por uma poética decolonial no ensino } \\
\text { superior: contribuições da didática na } \\
\text { formação de professores (as) }\end{array}$ & 2019 & Revista Pedagógica & $\mathrm{B} 2$ \\
\hline T23 & $\begin{array}{c}\text { Práticas de ensino no contexto das escolas } \\
\text { indígenas: diálogo de saberes e } \\
\text { epistemologias }\end{array}$ & 2014 & Educação em Foco & B1 \\
\hline T24 & $\begin{array}{l}\text { “Que criança feia! Por que a mãe dela está } \\
\text { feliz? Ela nunca vai ficar branca": reflexões } \\
\text { teóricas sobre crianças e relações raciais }\end{array}$ & 2015 & Educere et Educare & B2 \\
\hline T25 & $\begin{array}{l}3.100 \text { km entre práticas de educação } \\
\text { ambiental descolonializantes: experiências } \\
\text { didáticas na formação inicial de professores }\end{array}$ & 2018 & Educere et Educare & $\mathrm{B} 2$ \\
\hline T26 & $\begin{array}{l}\text { Uma reescrita contra-hegemônica da } \\
\text { formação de professores }\end{array}$ & 2010 & Nómadas & B1 \\
\hline
\end{tabular}

Fonte: dados da pesquisa (2020). 
Revista do Programa de Pós-Graduação em Educação da Unochapecó

ISSN 1984-1566 (on-line) ISSN 1415-8175 (impressa)

\section{PANORAMA DESCRITIVO DOS ARTIGOS}

A maioria dos artigos pertencia a revistas B1 (34,62\%), conforme o Gráfico 1 a seguir:

Gráfico 1 - Qualis das revistas na área de educação.

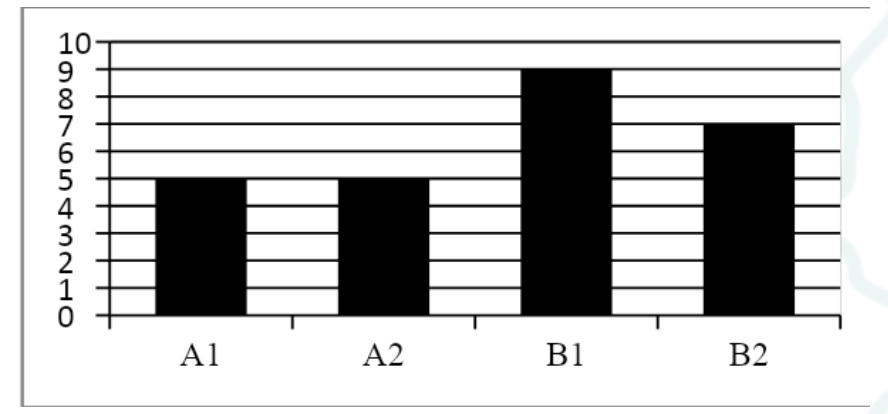

Fonte: dados da pesquisa (2020).

Como mostra o Gráfico 2, houve um pequeno crescimento das produções até 2014 e um aumento relativamente significativo nos anos de 2017 e 2018. Observa-se a ausência de trabalhos anteriormente ao ano de 2010, no que leva a ressaltar que o surgimento do grupo Modernidade/Colonialidade (formado por intelectuais latino-americanos, que assumiram uma miríade ampla de influências teóricas, atualizando a tradição crítica de pensamento latino-americano, oferecendo releituras históricas e problematizando velhas e novas questões para o continente) aconteceu no final do século XX, o que possivelmente refletiu nestes resultados.

Gráfico 2 - Distribuição diacrônica dos 26 artigos encontrados.

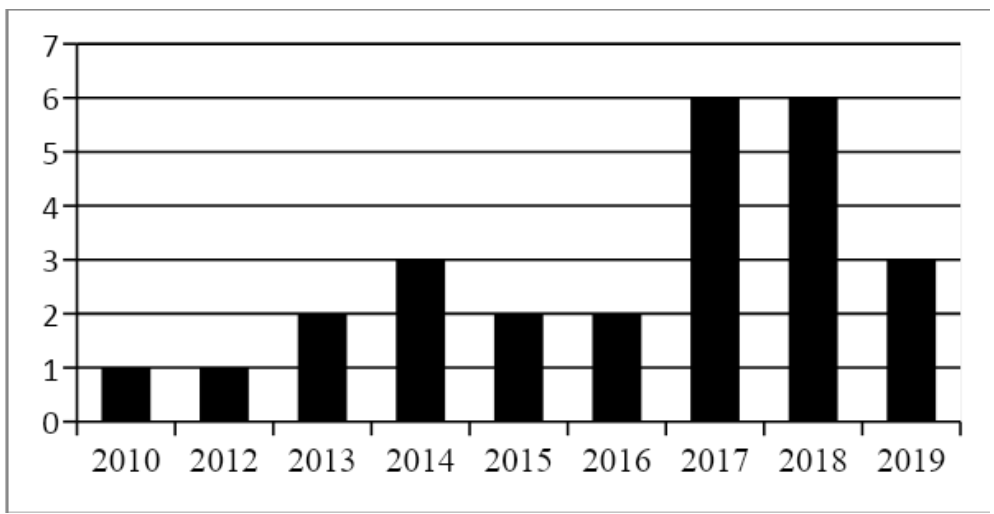

Fonte: dados da pesquisa (2020). 
Com respeito à natureza institucional na qual os autores estão vinculados, as produções são oriundas de universidades públicas, totalizando 65,38\%. Estes dados são evidenciamos na Figura 3:

Gráfico 3 - Natureza institucional.

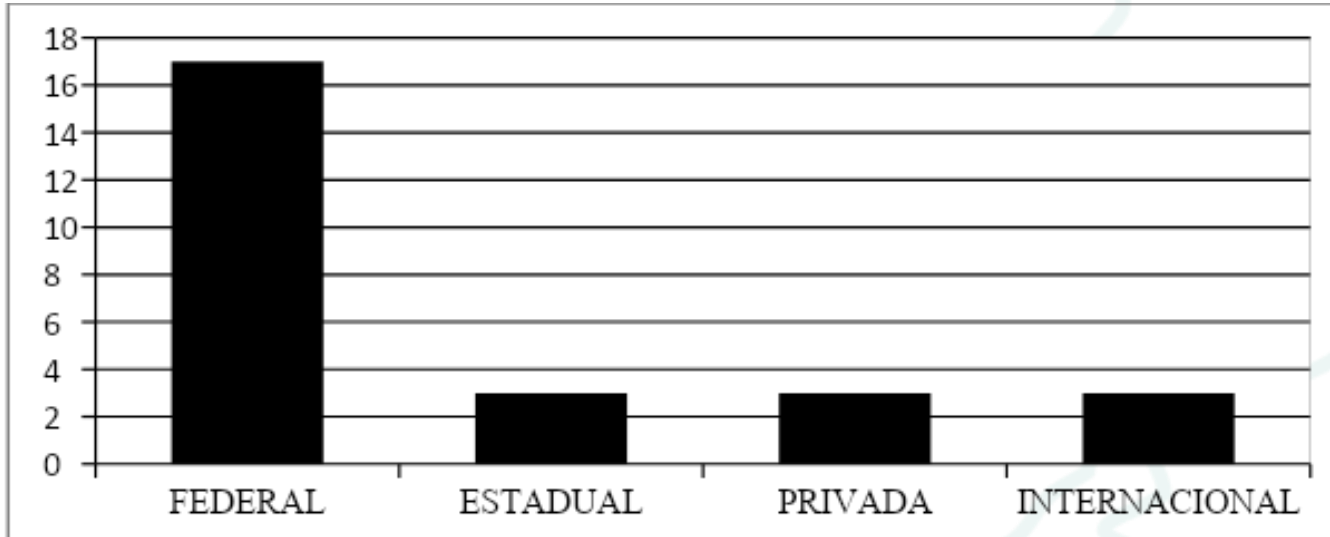

Fonte: dados da pesquisa (2020).

Constata-se um quantitativo maior de produções provenientes da Universidade Federal de São Carlos (4 trabalhos), seguida da Universidade Católica Dom Bosco (3 trabalhos), Universidade Federal do Rio de Janeiro (3 trabalhos) e Universidade Federal de Goiás (2 trabalhos). As demais universidades mantiveram-se com apenas um trabalho.

Quanto à distribuição geográfica dos artigos nacionais, há uma forte concentração na região sudeste, perfazendo um total de 52,17\% dos textos analisados. O gráfico 4 expõe a distribuição geográfica dos artigos:

Gráfico 4 - Distribuição geográfica. 


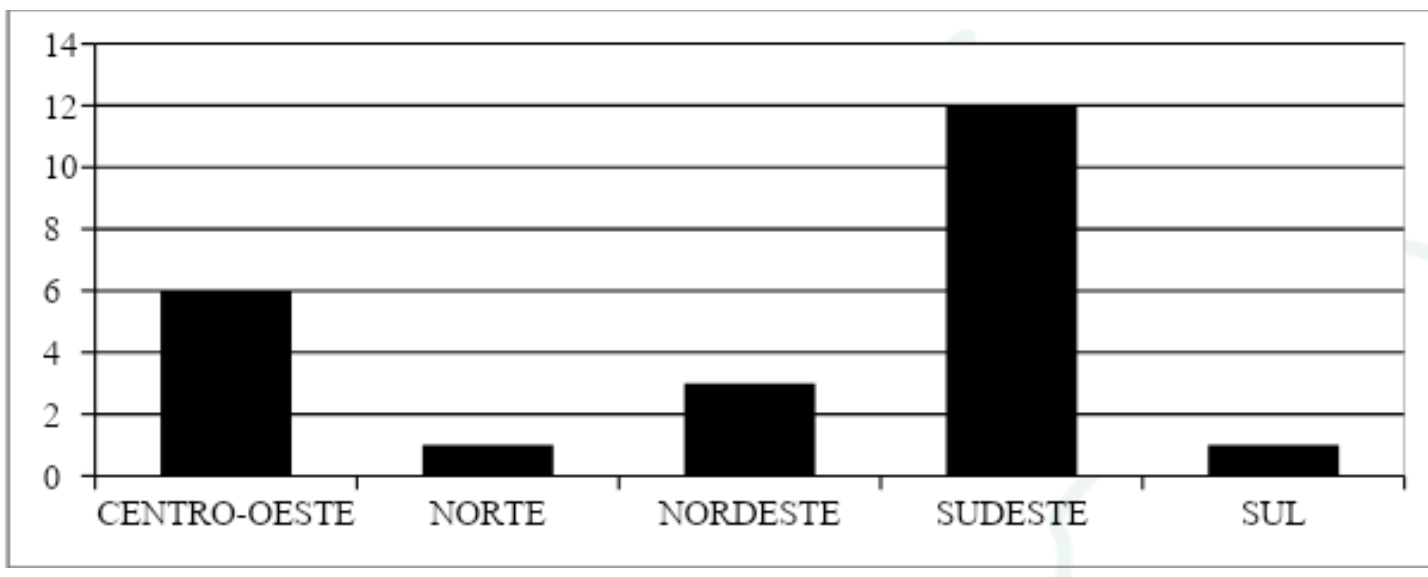

Fonte: dados da pesquisa (2020).

Estudos como os apresentados por Campos e Fávero (1994) e Ludke (2006), em levantamentos a respeito da pesquisa educacional, salientam que uma das características históricas é sua distribuição desigual no território brasileiro. A pesquisadora que mais produziu foi Adir Casaro Nascimento, com 3 trabalhos. Ela é professora da Universidade Católica Dom Bosco e suas linhas de pesquisas são: educação e interculturalidade, diversidade cultural, educação escolar indígena e criança indígena.

Dentre os autores mais citados estão Catherine Walsh (presente em 61,5\% dos projetos), Vera Maria Candau (em 26,9\%), Homi K. Bhabha (19,2\%), Paulo Freire (11,5\%), Walter Mignolo (11,5\%) e Aníbal Quijano (11,5\%). Catherine Walsh é professora e diretora do doutorado em Estudos Culturais da América Latina na Universidade Andina Simón Bolívar (sede do Equador), onde também dirige a Oficina Intercultural e a Cátedra de Estudos da Diáspora Afro-Andina. Ela é militante intelectual envolvida nos processos e lutas de justiça e transformação social e tem longa trajetória de acompanhamento aos processos de movimentos indígenas e afrodescendentes.

\section{ANÁLISE DOS ARTIGOS}

Os artigos T3, T5 e T24 objetivaram perscrutar o corpo legislativo frente a esta temática e posterior impacto após a sua implementação. T5 reconhece que, com o Plano Nacional de Educação (PNE), houve avanços no reconhecimento da pluralidade. Entretanto, segundo os autores, o foco dado a esta diversidade encontra-se nas 
preocupações com identidades coletivas específicas, tais como povos indígenas, quilombolas e na educação do campo.

As diretrizes do atual PNE orientam para a superação das desigualdades educacionais e para a promoção dos princípios do respeito aos direitos humanos, à diversidade cultural e à democratização do ensino. Não obstante, alteamos que para concretizar as almejadas transformações é necessária uma atuação integrada entre as instituições governamentais, a sociedade, a escola e a família.

T3 observou que a maioria dos professores que se graduaram anteriormente à implantação da lei 10.639/2003 no Mato Grosso do Sul não cursaram disciplinas que possibilitassem a efetivação de práticas pedagógicas que atendessem às diretrizes para a educação das relações étnico-raciais. Os autores também advertem que a ausência, nas secretarias de educação, de equipes preparadas para garantir a formação continuada de professores é um fator que interfere negativamente na efetivação de práticas pedagógicas atinentes com a construção de uma pedagogia intercultural e decolonial.

A Lei $n^{\circ} 10.639 / 2003$ citada por T3 institui a obrigatoriedade do ensino de História e Cultura Africana e Afro-Brasileira nos currículos da Educação Básica no Brasil. Ela representa o fruto da longa história de lutas pelo reconhecimento e pela reparação das desigualdades entre populações brancas e negras. No entanto, Almeida e Sanchez (2017) identificaram diversas dificuldades no processo de sua implantação no que tange a formação de profissionais de ensino, disponibilidade e divulgação de recursos à docência, intolerância religiosa, autonomia dos docentes, etc.

T10 e T19 fizeram uma revisão sistemática em artigos. T10 enfatiza a confluência das produções na evidência sobre a necessidade da formação inicial e continuada em congregarem o tema de modo consubstanciado e não como questões acessórias que podem ser vencidas por meio de uma disciplina, um evento ou cursos iminentes.

Ao longo de sua análise, T19 constata a pouca representatividade desta temática nas pesquisas científicas. Os autores salientam também sobre o fato de sermos um país miscigenado e de que o papel do professor deve ser vital no fortalecimento da valorização da cultura de cada povo.

Ressaltamos, desta forma, que não devemos agir conforme já dito anteriormente na introdução, embasados em Arroyo (2006 apud FERREIRA, 2011), como se 
convivêssemos com um protótipo único de aluno e, desta forma, com um currículo monocultural. Os próprios Parâmetros Curriculares Nacionais (PCN) elegeram como um dos seus temas transversais a pluralidade cultural com a recomendação ao atendimento das singularidades dos alunos.

Houve também dentre as produções (em T16) a análise de relatórios de licenciandos do Programa Institucional de Bolsa de Iniciação à Docência (PIBID). O estudo apresentado partiu do entendimento de que as práticas didáticas podem se comprometer com a construção de uma escola mais democrática, pois contribuíram com a visibilização de saberes outros que estão latentes, envolvendo os estudantes em reflexões sobre suas culturas, suas atitudes e procedimentos.

Os demais artigos fomentaram discussões acerca de práticas, usando, por exemplo, relatos de experiências e etnografias e eram atinentes em sua grande maioria de escolas indígenas. T1, T7 e T11 fizeram reflexões acerca da formação docente que ainda enfoca epistemologicamente o eurocentrismo, com procedimentos tradicionais, universalizantes e monoculturais.

Diante desta questão, há a transformação destes futuros professores em meros executores, sem qualquer vínculo com o contexto social o que poderá ser refletido em sua prática, transformando a escola como uma ilha completamente separada da sociedade. Além de também contribuir para a legitimação das desigualdades sociais e abandono à própria sorte aqueles discentes que por ventura não se enquadraram à metodologia adotada pelo professor.

Houve uma defesa por T7, T8, T11, T12, T17, T18, T22 e T23 para que futuros professores e professores formadores se constituam como pesquisadores em ação, construindo as intervenções e os discursos de formação em diálogo com as culturas docentes. Essas elucubrações vão ao encontro das asserções de Tardif (2012), inclusive sendo citado por T12, de que os professores recém-formados percebem que os conhecimentos adquiridos muitas vezes não se aplicam a sua ação cotidiana. Vale também ressaltar que buscar um horizonte de articulação entre a teoria e a prática, estreita a distância entre a escola e a universidade, com o estabelecimento de grandes ganhos para ambas as instituições, no sentido de ser imprescindível para formação do futuro professor 
e poder contribuir na formação contínua do professor da escola e do professor universitário.

Foi também estimulada por T12 a troca de experiência entre os pares, consolidando espaços de formação mútua, nos quais cada professor seria chamado a desempenhar, simultaneamente, o papel de formador e de formado. Desta forma, há a percepção de que as identidades apresentam caráter provisório e estão em construção, conforme já exteriorizado anteriormente fundamentando-nos em Pimenta (1997).

Para finalizar, como a grande maioria dos trabalhos elucidou acerca de práticas com licenciandos em escolas indígenas, vale externar a evidência dos autores em relação à limitação da formação no que tange a educação indígena, que segundo os mesmos, é muito generalista e vaga. Inclusive menciona-se a ausência de diretrizes para a formação de professores indígenas (T12).

\section{CONSIDERAÇÕES FINAIS}

O sistema educacional brasileiro é uma herança do modelo educativo colonial, sustentado em orientações eurocêntricas que vão em prol da ideologia dos governantes, que sob a lógica economicista, coaduna com os interesses internacionais. Ele legitima processos hegemônicos, estando a favor de alguns e abandonando outros à própria sorte e age como se o aluno fosse um bloco homogêneo.

Sob esta ótica, tentando romper com estes condicionamentos, o texto abordou a pedagogia decolonial que valoriza as multiculturas, procurando dar visibilidade aos grupos subalternizados e polemizar postulados num processo dinâmico, democrático e de interrelação. Nesta perspectiva, há o entendimento de que educar é um ato político, que tenciona superar as desigualdades, exclusões sociais e libertar o sujeito de condicionamentos pré-determinados.

Diante da compreensão de que a partir do instante em que forem aplicados novos caminhos para a formação docente, o reflexo poderá ser nitidamente observado na educação básica, este trabalho procurou apresentar um panorama descritivo dos artigos que tratam da pedagogia decolonial nos cursos de formação inicial e continuada de professores. Objetivou investigar de que forma as abordagens decoloniais estão sendo 
sugeridas na literatura com relação aos mesmos e quais são as principais menções destes trabalhos frente a esta temática.

Foram analisados 26 trabalhos na base de dados Google Acadêmico, que demonstraram uma distribuição regional desigual das produções no território brasileiro, em sua maioria no sudeste ( $46,15 \%)$; além de manifestarem que sua natureza institucional remete-se a universidades públicas federais. O recorte temporal dos trabalhos encontrados se deu entre 2010 e 2019.

Houve elucidação das licenciaturas incentivarem às discussões dos temas educacionais de forma problematizadora, desprendendo-se dos procedimentos tradicionais, universalizantes e monoculturais. Além de ajudar os licenciandos a construírem suas identidades e de se constituírem pesquisadores em ação (numa parceria entre professores da universidade, professores licenciandos e professores da escola). Eles inclusive evidenciaram a necessidade da formação congregar estas questões de modo consubstanciado e não de forma subsidiária.

Por fim, vale ressaltar que a grande maioria esteve motivada a refletir sobre a formação de docentes para a escola indígena, afirmando que a mesma é limitada e insuficiente para a consolidação de uma escola inclusiva com qualidade. No entanto, ratificamos que estas questões também devem ser ponderadas para grupos que foram perdendo suas identidades, como a população negra no período colonial. Inclusive o próprio corpo legislativo faz referências na Lei de número 10.639/2003, instituindo a obrigatoriedade do ensino de sua cultura nos currículos da Educação Básica no Brasil, objetivando construir uma nova realidade, livre das amarras e dos controles do pensamento hegemônico.

\section{REFERÊNCIAS}

ALMEIDA, Marco Antônio Betine; SANCHEZ, Livia Pizouro. Implementação da Lei 10.639/2003: competências, habilidades e pesquisas para a transformação social.

Proposições, v. 28, n. 1, p. 55-80, abr. 2017.

BRASIL. Conselho Nacional de Educação. Diretrizes Curriculares Nacionais para a Formação de Professores da Educação Básica, em nível superior, curso de licenciatura, de graduação plena. Parecer CNE/CP n. 9 de 8 de maio de 2001. 


\section{REVISTA}
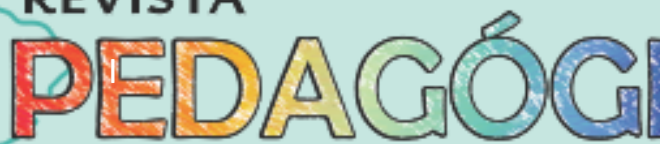

Revista do Programa de Pós-Graduação em Educação da Unochapecó ISSN 1984-1566 (on-line) ISSN 1415-8175 (impressa)

BRUNO, Jéssica Santana. (Inter)ações afirmativas: Políticas de sentido sobre a colonização/decolonização do conhecimento no currículo e na formação docente. 2018. Dissertação (Mestrado em Estudos Interdisciplinares sobre a Universidade) - Instituto de Humanidades, Artes e Ciências, Universidade Federal da Bahia, Salvador, 2018.

CAMPOS, Maria Malta; FÁVERO, Osmar. A pesquisa em educação no Brasil. Cadernos de Pesquisa, n. 88, p. 5-17, fev. 1994.

CANÁRIO, Rui. A escola: o lugar onde os professores aprendem. Psicologia da Educação, n. 6, p. 9-27, 1998.

DIAS, Rosanne Evangelista; LOPES, Alice Casimiro. Competências na formação de professores no Brasil: o que (não) há de novo. Revista Educação \& Sociedade, v. 24, n. 85, p. 1155-1177, dez. 2003.

DIAS, Rosimeri Oliveira. Produção da vida nos territórios escolares: entre universidade e escola básica. Psicologia e Sociedade, v. 24, n. especial, p. 67-75, 2012.

FERREIRA, Fernanda Nunes. Multiculturalismo e currículo escolar: desafios e possibilidades para o novo milênio. Pesquisa em Pós-Graduação - Série Educação, n. 7, p. 133-142, 2011.

GATTI, Bernardete Angelina. Formação de professores no Brasil: características e problemas. Educação \& Sociedade, v. 31, n. 113, p. 1355-1379, out.-dez. 2010.

LOPES, Alice Casimiro. Políticas de currículo: competencias y asignaturas. In: IX CONGRESO NACIONAL DE INVESTIGACIÓN EDUCATIVA, 2009, México. Anais do IX Congreso Nacional de Investigación Educativa. México: COMIE, 2009, p. 87-104.

LÜDKE, Marli. Educação formal e não formal, processos formativos e saberes pedagógicos: desafios para a inclusão social. In: XIV ENDIPE, 2006. Recife/PE. Anais do XIV ENDIPE. Recife/PE: Universidade Federal de Pernambuco, 2006.

MATEUS, Elaine. Conversa com Elaine Mateus. In: SILVA, K. A. da.; ARAGÃO, R. C. (Org.). Conversas com formadores de professores de línguas: avanços e desafios. Campinas, SP: Pontes Editores, 2013. p. 93-111.

MIGNOLO, Walter. Capitalismo y geopolítica del conocimiento: El eurocentrismo y la filosofía de la liberación en el debate intelectual contemporáneo. Ciudad Autónoma de Buenos Aires: Del Signo, 2014.

MIRANDA, Cláudia. Currículos decoloniais e outras cartografias para a educação das relações étnico-raciais: desafios político-pedagógicos frente à Lei $n^{\circ} 10.639 / 2003$. Revista da Associação Brasileira de Pesquisadores/as Negros/as, v. 5, n. 11, p. 100-118, 2013. 
Revista do Programa de Pós-Graduação em Educação da Unochapecó ISSN 1984-1566 (on-line) ISSN 1415-8175 (impressa)

MOURA, Eduardo Santos. Inquietações, decolonialidade e desobediência docente: formação inicial de professores/as de artes visuais na América Latina. Revista Papeles, v. 9, n. 18, p. 21-33, jul-dez. 2017.

NETO, João Colares Mota. Paulo Freire e Orlando Fals Borda na genealogia da pedagogia decolonial latino-americana. Folios, n. 48, p. 21-33, 2018.

PIMENTA, Selma Garrido. Formação de professores - saberes da docência e identidade do professor. Nuances, n. 3, p. 5-14, set. 1997.

POSO, Fabiana de Freitas; MONTEIRO, Bruno Andrade Pinto. Análise dos relatórios de licenciandos em Biologia de uma universidade pública acerca da temática avaliação da aprendizagem. Pesquiseduca, v. 11, p. 60-77, 2019.

ROCHA, Alessandra Fontes Carvalho. Processos e práticas decoloniais na formação de professores. RELACult - Revista Latino-Americana de Estudos em Cultura e Sociedade, v. 3, n. especial, p. 1-19, dez./2017.

SACRISTÁN, José Gimeno. O currículo: uma reflexão sobre a prática, 3. ed. Porto Alegre: Artmed, 2000.

SILVESTRE, Viviane Pires Viana. Práticas problematizadoras e de(s)coloniais na formação de professores/as de línguas: teorizações construídas em uma experiência com o Pibid. 2016. Tese (Doutorado em Letras e Linguística) - Faculdade de Letras, Universidade Federal de Goiás, Goiânia, 2016.

TARDIF, Maurice. Saberes e formação profissional. Petrópolis: Vozes, 2012.

VEIGA, Ilma Passos Alencastro. Didática: entre o pensar, o dizer e o vivenciar. Ponta Grossa: Ed. UEPG, 2012.

WALSH, Catherine E. Interculturalidad y colonialidad del poder: un pensamiento y posicionamiento "otro" desde la diferencia colonial. In CASTRO-GÓMEZ, S.; GROSFOGUEL, R. El giro decolonial: reflexiones para una diversidad epistêmica más allá del capitalismo global. Bogotá: Siglo Del Hombre Editores, 2007.

ZANLORENZI, Marcos Aurélio.; OLIVEIRA, Anderson Martins. Educação Matemática em territórios contestados: um currículo diferenciado para as ilhas do litoral do Paraná. Educação Matemática Pesquisa: Revista do Programa de Estudos Pós-Graduados em Educação Matemática, v. 19, n. 3, p. 209-229, 2017.

Enviado em: 02-04-2020

Aceito em: $20-10-2020$

Publicado em: 